\title{
How Vague Can Your Patent Be? Vagueness Strategies in U.S. Patents ${ }^{1}$
}

\begin{abstract}
Patent claims define the protection scope of the intellectual property sought by the patent applicant or patentee. Broad claims are valuable as they can describe more expansive rights to the invention. Therefore, if these claims are too broad a potential infringer will more easily argue against them. But if the claims are too narrow the scope of protection of the intellectual property is greatly reduced. Patent claims have to be, on the one hand, determinate and precise enough and, on the other hand, as inclusive as possible. Therefore patent applicants must find a balance in the broadness of the scope defined by their claims. This balance can be achieved by the choice of words with a convenient degree of semantic indeterminacy, by the choice of modifiers or other strategies. In fact, vagueness in patent claims is a desirable characteristic for such documents. A quantitative and qualitative analysis of a corpus of 350 U.S. patents provides a promising starting point to understand the linguistic instruments used to achieve the balance between property claim scope and precision of property description. To conclude, some issues relating vagueness and pragmatics are suggested as a line of further research.
\end{abstract}

\section{Introduction}

Bertrand Russell (1923: 84-92) $)^{2}$ said that language is inherently vague. Vagueness is seen often as a problem when it comes to interpret legal language (Mellinkoff, 1963; Dascal/Wróblewsky, 1988; Kennedy, 2002; Solan, 2005). But if we approach vagueness from the point of view of the drafter of legal documents, then it becomes a useful and desirable feature (Endicott 2001, Frade 2002, Adams 2004, Butt/Castle 2006, Anesa 2007, Engberg/Heller 2008). This paper proposes, following Prampolini (1998: 98) and Williamson (1996: 86), that vagueness allows a flexible use of the required precision ${ }^{3}$ to meet the communicative purposes of the U.S. patent genre. Therefore, the main goal of this document is to describe the vagueness strategies used by patent applicants to balance their commercial interests with the requirements to obtain a patent. More specifically, as Myers (1996: 6) explains, the intentional marked choice of words allows referring to a range of referents instead of selecting a more specific form. Therefore, Myers (1996: 6) and Quine (1963: 128) see this choice as a communication strategy and not a failure in the use of explicitness.

1 This paper is the extended version of a paper presented at the $2^{\text {nd }}$ International Conference in the $360^{\circ}$ Series held at the Aarhus School of Business and Social Sciences. I wish to thank the Universidad Politécnica de Madrid for its partial funding of the conference attendance; Dr. Engberg for suggesting that I presented on this topic; Dr. Pierucci for her help with the bibliography; Dr. Anesa for her comments on one of the drafts; and the reviewers for their very useful comments.

2 Although, as Mark Colyvan reminds us in his 2001 paper "Russell on Metaphysical Vagueness"(Principia, Vol 5, $\mathrm{N}^{\mathrm{o}} 1-2$, pp. 87-98), the debate of whether vagueness is a feature of language or a feature of the world (ontological or metaphysical vagueness) is still open and alive.

3 Title 37, Code of Federal Regulations $\$ 1.57 . c .1$ and $§ 1.71$.a-b.

\footnotetext{
* Ismael Arinas

Universidad Politécnica de Madrid, E.T.S. Ingenieros Industriales

Dept. Lingüistica Aplicada C.T.

José Gutiérrez Abascal 2

Madrid 28006, SPAIN

ismael.arinas@upm.es-ismael.arinas@gmail.com
} 
For this research, I compiled a corpus of 350 U.S. electromechanical patents ${ }^{4}$ granted between 1999 and 2009. For the analysis of the corpus, I used the freeware Antconc 3.2.1w5. The corpus amounts to about 3 million tokens and 31,219 token types.

I will begin with an overview of the U.S. patent genre to provide a relevant context that explains the communicative need for vagueness and its use limitations. This overview is followed by a description of the methodology used to analyse the patent corpus. Then, I will present Manfred Pinkal's (1985/1995) taxonomy of vagueness and how this semantic trait can become a useful tool for the communicative purposes of some legal genres. I will base my corpus queries on Channell's (1994: 42-163) classification of vague language. Channell's approach (1994: 165-194) is also used to explain the possible reasons for using vagueness in patents.

\section{U.S. Patents and Patentability Requirements}

Patents are a genre that combines features of technical and juridical texts, in other words, they are interdisciplinary in their use of language (Brugnoli, 2007: 44). Up to now more than 7.5 million have been issued and during 2009 the United States Patent and Trademark Office (USPTO) granted $191,474^{6}$ patents $(96,678$ to foreign applicants). Of these, 167,349 were utility patents, 23,116 were design patents, and 1,009 were plant patents. Utility patents include processes, machines, manufactures and composition of matter. For this study, I have only considered utility patents.

Bazerman (1999: 90) sees patents as being part of a process institutionalised to obtain a property:

To create profit from an idea, the idea has to be transformed into an ownable piece of property assigned to an individual. The procedure for this transformation must identify an idea as an invention, establish the limits of the idea (that is, identify the size of the property), establish the period of ownership, and designate the owner $[\ldots]$.

This property-obtention process consists of words and symbols (Bazerman, 1999: 90). Essentially, the information contained in a patent could be the same as that contained in a technical journal. But switching from writing journal articles to writing patents does not seem to be a straightforward transition (Myers 1995: 63). The discourse communities of patents and journal articles are somewhat different, so are their communicative conventions and purposes. Again, the whole process leading to a patent grant is very different from that leading to the publication of a paper. According to Myers (1995: 58), there is a dichotomy between science/discovery/knowledge and technology/invention/property which would explain why the same information can exhibit such important differences when embodied in either a journal paper or a patent.

\footnotetext{
However the patent status is only gained through the successful completion of certain acts that must go through regulatory tests within a highly developed social system. Moreover, once the regulatory agency grants the patent there are other parties (such as competitive producers) who would wish to undo the patent, limit it, or otherwise contest it - thereby making what has been determined indeterminate again, so that it might be redetermined in a way more favourable to the competitor's interests. (Bazerman 1993: 6)
}

A patent application containing, among other data, a legally and technically meaningful description of the property claimed is an essential step of those acts mentioned above by Bazerman. Before being granted, this application will be tested by professional examiners on its persuasiveness regarding the novelty, non-obviousness ${ }^{7}$ and utility of the property being described (Frobert-Adamo, 2000: 161). The rules to interpret the breadth of the scope of the property claimed in the application are spelled out in section 2100 of the Manual of Patent Examining Procedure (MPEP) ${ }^{8}$.

4 They can be obtained for free from the US Patent and Trademark Office website: http://www.uspto.gov .

5 Developed by Laurence Anthony and downloadable from: http://www.antlab.sci.waseda.ac.jp/software.html

6 http://www.uspto.gov/web/offices/ac/ido/oeip/taf/reports.htm

7 Known as Inventive Step in the European patent system.

8 Manual of Patent Examining Procedure (MPEP) on: http://www.uspto.gov/web/offices/pac/mpep/mpep.htm 
Still, all this happens at the risk of losing totally or partially the grant of the property to a competitor (Bazerman, 1990: 90). Roberts (2007: 7-9) explains that a patent has to satisfy several stakeholders in the patenting process: the validity people and the infringement people.

With the validity people, Roberts refers to the patent examiners of the USPTO (pre-grant assessment), some courts, and the U.S. Re-examination Forum (post-grant assessment). Patent examiners are the first to assess a patent application and they are not concerned with the financial feasibility of a pending patent. They check that the invention meets the legal requirements to be considered patentable, that the invention is sufficiently described, and that this description is clear and supported. By sufficiently described, the legislation (Consolidated Rules, Title 37 Code of Federal Regulations, $\S 1.71^{9}$ ) requires the description of at least one preferred embodiment of the invention in a way that enables a person skilled in the art to make it and use it. This description has to show that the invention is new and non-obvious. The courts and the U.S. Re-examination Forum use a slightly different set of criteria to assess the validity of granted patents: now there are commercial interests at stake. This post-grant validity assessment is centred on newly unearthed prior art issues (evidence questioning the novelty of the granted patent).

The infringement people class is made up by those affected commercially by a specific patent. They are essentially licensees and competitors whose commercial behaviour may be controlled by the strategic issue of patents. In the words of Roberts (2007: 9), the patentees, the licensees, and the competitors are interested in "how much does the patent cover?" The reason is that we are talking about the protection of intellectual property. The more it is protected, the greater financial potential there is for the patentees. The less scope covered, the more business opportunities that remain unclaimed and available to competitors and licensees. It is in the interest of competitors to find evidence of intellectual property trespassing (infringement of valid existing patents). Licensees are interested in discovering unclaimed patches of intellectual property so they can carry out their activities without licensing costs.

The first article of the U.S. ${ }^{10}$ Constitution (section 8) states that inventors should be rewarded in exchange for the disclosure of their discoveries. To obtain this reward, or status as Bazerman (1993: 6) explains, the State allows for the possibility of transforming a particular idea into exclusive property. This transformation is achieved through words and symbols that identify an invention as the claimed property, establish the size of this property, determine the duration of this property, and assign it to an owner (Bazerman, 1999: 90). So by granting the status of private property to an inventive idea, the State is providing the patent applicants the right to exclude others from producing, selling, and using that property during 20 years. In this period, the patentees should be able to profit from the exclusive rights over their inventions. It is in the interest of the inventors to be as vague as allowed by the patent examiners and courts when it comes to define the limits of their property.

\title{
3. What is Meant by Vagueness
}

I will consider here vagueness as opposed to precision. As Adams (2005: 85) states when referring to contract drafting:

\begin{abstract}
Vagueness derives from imprecision. It is to be distinguished from ambiguity, which derives from alternative inconsistent meanings. While ambiguity is always a detriment to good drafting, vagueness is a standard drafting tool. The odds are that any given contract will contain one or more vague provisions.
\end{abstract}

Arntz/Sandrini (2007: 135) and Bhatia (2005: 337) tell us that there is a tension between precision and indeterminacy in legal language. These authors explain that in specialist communication precision is crucial to avoid any form of ambiguity, but laws and statutes define general rules which

9 United States Code of Federal Regulations Title 37 - Patents, Trademarks and Copyrights available on: http://www. uspto.gov/web/offices/pac/mpep/consolidated_rules.pdf

10 http://www.usconstitution.net/const.html\#A1Sec8 
must be comprehensible and adaptable to changing circumstances. Arntz/Sandrini conclude that as a result, regulations incorporate varying degrees of indeterminacy in the different legal systems, which is coherent with Bhatia's (1993: 103) description of legal language as having an allinclusive nature. The problem when interpreting these vague regulations would derive from what Kennedy (2002: 1) calls a lack of specification of the implicit standard in the lexical entries. For example, in (1) and (2) below, the implications of preferably and desirably are not defined against any recognized technical standard.

(1) Such welds are preferably not continuous, but rather are short welds, spaced approximately one foot apart. (United States Patent 6,763,635)

(2) The connectors desirably have a diameter of no more than 2.75 inches and, preferably, no more than 2.05 inches. (United States Patent 6,745,854)

According to Pinkal (1995: 12-15), we can distinguish between communicative underdeterminacy (when the receiver receives less information than expected in a given situation) and semantic indeterminacy (when the receiver cannot decide whether the utterance is true or false). The two concepts are compatible as they represent two views of the same problem. Pinkal further distinguishes two categories within semantic indeterminacy: ambiguity (see example 3 below) which arises when receivers require more precision to understand an utterance; and vagueness (see example 4 below) which takes place when an utterance, although imprecise, can be understood without further detail. Both ambiguity and vagueness refer to borderline concepts or words (Van Deemter, 2010: 8). Endicott (2001: 379) defines these borderline concepts as "cases in which the application of the standards of the law is subject to doubt and disagreement".

(3) Thus a modified tractor hitch and corresponding modified implement pinning structure solving the aforementioned problems is desired. (United States Patent 6,679,512)

(4) The brake lining 26 is preferably made up of four (4) brake lining block segments ... (United States Patent 6,169,441)

From the point of view of philosophy, Quine (1960: 127) provides a justification for the use of vagueness:

\footnotetext{
Vagueness is not incompatible with precision. As Richards has remarked, a painter with a limited palette can achieve more precise representations by thinning and combining his colors than a mosaic worker can achieve with his limited variety of tiles, and the skillful superimposing of vagueness has similar advantages over the fitting together of precise technical terms.
}

As Prampolini (1998: 97) and Williamson (1996: 85) observe, vagueness provides language with a needed flexibility and therefore vagueness is gradable according to the communicative needs of the document. Quine (1960: 128) specifically identifies the relationship between vagueness and the goals of legal language:

Sentence values whose truth values hinge on vagueness usually command interest only in specialized
studies, if at all, and the rulings adopted to resolve the obstructive vagueness are adopted only locally
for the purposes in hand. One fertile field of illustrations is law; another is that of almanac firsts.

Vagueness should not be confused with wordiness. As Mellinkoff (1963: 401) reminds us, precision does not depend on the number of words: sometimes, to be precise one needs to use many words. Examples (5), (6) and (7) illustrate an increasing level of precision but the verbosity varies independently from the vagueness degree. In (5) vagueness is the result of the generality required by a definition. In (6) precision increases and wordiness decreases, but there is still a range of values that makes the statement true. Example (7) is the most precise of the three, but also the one that uses more words.

(5) Hysteresis is a phenomenon where a measured quantity depends on the direction of a process. (U.S. Patent 6,738,220). 
(6) The inside diameter of a 5-inch casing can range from 4.5 to 4.8 inches. (U.S. Patent 6,679,341).

(7) A $10 \mathrm{HP}$, YANMAR diesel engine 1 connected to a $115 \mathrm{~V}, 2.5 \mathrm{KW}$ electric generator 2 and a belt driven positive displacement pump (CAT) 3 capable of pumping 4 gallons per minute at 3000 psi is bolted inside one end of a protective steel roll cage 43. (U.S. Patent 6,761,135).

Mellinkoff (1963: 416) makes another relevant point applicable to the context of patents: precision in the law does not imply intelligibility and sometimes, for the sake of better understanding, vagueness is more convenient. Endicott (2001: 379) provides three reasons for the convenience of vagueness:

(1) that lawmakers use vague laws because precision is not always desirable; (2) that because law is "systemic," enactments formulated in precise language do not always make precise laws; and (3) that law must perform functions that can only be performed by means of vague standards.

As the computational linguist Van Deemter (2010: 10) summarizes: "sometimes vagueness is simply unavoidable, while on other occasions vagueness is actually preferable to precision". Thus, we can argue that vagueness would not be a problem to meet the clarity requirement contained in 35 U.S.C. $\S 112^{11}$ and 37 C.F.R $\S$ 1.57.c.1. Because patents share with statutes the need to adapt to future circumstances, "they have to be future proof" (Roberts, 2007: viii), and "the Patent Attorney has to anticipate everything that could go wrong for the next twenty years and make sure this document [the patent] covers it" (Roberts, 2007: ix). Vagueness allows, over time, to interpret, patents as covering similar and "undreamed of inventions" at the time of the patent application (Myers, 1996: 8). The patent text must be able to define a property in several forums in the future (Myers, 1996: 8).

\section{Motivation for Vagueness in U.S. Patents}

Myers (1996: 4 and 7) explains that vagueness can have a strategic motivation and he expects patent rhetoric to rely on its use to create a persistent text and to extend academic knowledge to the legal and commercial arenas. Channell (1994: 173-188) proposes a set of motivations for being vague. I have selected from this set the following five that seem to coincide with the strategic communicative motivations in U.S. patents of "mapping specific instances onto general categories over time." (Myers, 1996: 6):

- Giving the right amount of information: according to the second part of the Gricean maxim of quantity, the patent writers do not need to be more informative than required. This would account for recurring to vagueness in patent descriptions. Howells/Scholderer (2008:1) assert the falsehood of the legal theory of quid pro quo which assumes that the disclosure of technical information in patents would remain hidden as a trade secret without intellectual property protection. These authors indicate that the real function of patents would be securing the incentive to invent and develop, because patent specifications identify each invention with respect to prior art but they do not really enable the making of the new invention. This vagueness would make the patent defensible against rival patents in court and would prevent the competitors from finding patentable alternatives of the patented invention.

- Deliberately withholding information: a defensive tactic used when the patent writers consider that they have to hide some precise information. In the case of patents, one invention can be divided into several sub-inventions, thus hiding information through vagueness in one allows for multiple patents of one inventive idea.

- Using language persuasively: vague numerical expressions support the writers' argument and present data in a truthful manner. Patent descriptions are expected to be truthful within the

11 The specification shall contain a written description of the invention, and of the manner and process of making and using it, in such full, clear, concise, and exact terms as to enable any person skilled in the art to which it pertains, or with which it is most nearly connected, to make and use the same [...]. 
knowledge of the applicants:

Each individual associated with the filing and prosecution of a patent application has a duty of candor and good faith in dealing with the Office, which includes a duty to disclose to the Office all information known to that individual to be material to patentability as defined in this section. (Title 37, Code of Federal Regulations, § 1.56.a)

As patents deal with innovation, very precise statements have two disadvantages: they restrict the future scope of an insufficiently known invention and may present the information as proven facts when it may not be the case.

- Lacking specific information: when there is no certainty about the truthfulness of the statement, the speaker may choose to be vague. As the information in patent descriptions is required to be accurate to the best knowledge of the applicants, vagueness seems to be an efficient way to comply with this requirement.

- Self-protection: according to Channell (1994: 188) this is "used as a safeguard against being later shown to be wrong". As far as patents are concerned, this motivation is coherent with what has been already explained.

\section{Corpus Description and Tools for its Analysis}

The corpus used for this study is a collection of 350 utility patents downloaded from the USPTO website. The oldest patents in this corpus are from 1999 and the latest ones from 2009. To select the patents, I searched on the USPTO patent database for electromechanical terms (gear, clutch, brake, engine, coil, sensor, pyrolitic, piezoelectric etc.) and hyperonyms (substance, liquid, vehicle, method, apparatus, etc.). I randomly selected from these queries those patents that were within the 1999-2009 time bracket until I collected approximately three million tokens. Table 1 below provides the basic data that describe the characteristics of this corpus and the number of keywords selected for this study.

\begin{tabular}{|l|c|}
\hline Number of documents & 350 \\
\hline Number of tokens & $3,070,565$ \\
\hline Number of different tokens (Types) & 31,219 \\
\hline Type/Token ratio & $1.016 \%$ \\
\hline Average tokens per document & $8,773.04$ \\
\hline Number of Keywords used & 300 \\
\hline
\end{tabular}

Table 1. Data describing the U.S. patent corpus used

I decided that instead of checking lists of vague words in legal language mentioned by other authors (Mellinkoff 1963, Tiersma 1999), I should obtain a list of keywords from my patent corpus that could have a vague meaning in U.S. patents. Obviously, once the list of keywords is available, it can be compared to previous research. Antconc $3.2 .1 \mathrm{w}^{12}$, among other tools, offers the possibility of extracting keywords from a corpus. It allows the choice between two possible statistical measures of keyness: the Chi-squared test and the Log-likelihood test. Both tests require a reference corpus for extracting the keywords of the studied corpora. Taking the token frequencies in the reference corpus as a standard, the software calculates the expected frequency for each token of the studied corpus. It then compares the expected frequency against the real frequency found for each token of the studied corpus. If the frequency of a token is higher than the expected fre-

12 The software used for the corpus analysis (Antconc 3.2.1w) has been developed by Professor Laurence Anthony at Waseda University, Japan. Apart from extracting the keywords, this software allowed me to detect the noun clusters mentioned in tables 6, 7, 8, and 9 below. Examples (1) through (42) were detected in the corpus with the concordance function of Antconc. 
quency, then the software assigns to this token a keyness value. According to Rayson \& al. (2004: 3) and Rayson/Garside (2000: 2) the Chi-squared test is less reliable than the Log-likelihood test, so I have chosen this second test as the method for extracting the keywords from my corpus. I used the 100 million-word British National Corpus as reference corpus for the extraction. Then, I used as seeds for my corpus queries a selection of vague words from among the 300 with the highest keyness value.

\section{Channell's Vagueness Categories in U.S. Patents}

Channell (1994: 42-73, 95-117, and 119-142) also proposes a classification of vagueness markers that can be applied to the context of U.S. patents. In this section I will start by illustrating with examples from my corpus what she denominates vague category identifiers (Channell, 1994: 123). I continue with examples of the use of approximators (Channell, 1994: 44). The section continues with examples of approximating quantities with non-numerical vague quantifiers (Channel, 1994: 95). Finally, I provide examples of how modals, adverbs and conjunctions can be used to introduce vagueness in patents.

\subsection{Vague Category Identifiers in U.S. Patents}

Channell (1994: 122) defines vague category identifiers as expressions which through their prototypicality allow the receiver to identify the set to which the expression belongs. Channell's research focused on the use in spoken English of expressions such as "or something, and things like that, or whatever" to transform nouns into categories. But patents, being part of a much more formal convention, achieve categorization through the use of semi-technical hyperonyms. Joan Cutting (2007: 223-225) classifies these expressions under three categories: Metonymical proper nouns, superordinate nouns, and general nouns.

Metonymical proper nouns are used as labels to refer to unnamed entities ${ }^{13}$ (Cutting, 2007: 224). Superordinate nouns are general labels for referring to specific members (Cutting, 2007: 224). General nouns are for Cutting (2007: 225) on the borderline between a lexical item and a personal pronoun. All these could be grouped for practical reasons under what Ivanič's calls carrier nouns (1991: 95-96) which are words carrying a context-dependent meaning attached to their dictionary meaning. He proposes a list of such nouns that can be used in academic language (1991: 96)

Ivanič's list includes nouns which are simultaneously vague enough to refer to a set of more specific concepts and somewhat anaphoric as they can be used to refer to previous circumstances mentioned in the text. See examples (8) and (9):

(8) This function determines the shape of the lower edge 16. (U.S. Patent 6.763,810).

(9) Another problem with known zero turn tractors is related to the required weight distribution. (U.S. Patent 6,6316,07)

This list includes several vague words that you may find playing an important role in the patent section entitled Background of the Invention. Nevertheless, both the backgrounding nature and short length of this section have two consequences regarding the keyness ranking of its vocabulary in patents: (a) the vocabulary is essentially different from the rest of the patent; (b) it represents a small proportion of the total vocabulary of the corpus. Therefore, Ivanič's carrier nouns appear ranked in my keyword list below the first 300 keyword-limit used for this paper.

The length of a patent title is legally limited to a maximum of 500 characters ${ }^{14}$. This allows for precision while remaining concise. Nevertheless, some patent applicants, in an effort to reconcile

13 She gives the following example: "How's your Chomsky" where "Chomsky" refers to a project on professor Chomsky.

14 Consolidated Patent Rules $\S 1.72$, paragraph (a). Title 37 - Code of Federal Regulations Patents, Trademarks, and Copyrights. 
concision and vagueness, risk both trespassing the intellectual property of others and damaging their persuasiveness in terms of novelty as the following three titles $(8,9$ and 10$)$ of real patents illustrate:

(10) Vehicle (U. S. Patent 6,588,858)

(11) Personal watercraft (U. S. Patent 6,764,360)

(12) Transmission (U. S. Patent 6,763,736)

Roberts (2007: 63) indicates that for U.S. patents, any part of the patent text can be used to interpret the scope of the claims, thus, vague titles cannot destroy the validity of the claims.

In other cases, the word choice of titles is a surprising combination of vague terms to describe property for which a single word term is already available:

(13) Tornado generation method and apparatus (United States Patent 6,082,387)

(14) Image forming apparatus (United States Patent 7,558,509)

(15) Light scanning apparatus (United States Patent 7,557,976)

(13) corresponds to a vacuum cleaner, (14) to a printer or photocopier, and (15) to a document scanner. There are, of course, patents where the more precise version is mentioned. Nevertheless, the latter are renouncing to include under the umbrella of patent protection future and unknown applications of the invention at the time of its patenting. As Williamson (1996: 86) reminds us: "too much precision is a bad thing even in scientific language, restricting its adaptability to new evidence."

Outside the titles, conceptual vagueness is also frequent in descriptions and claims, so let us consider the vague behavior of the following 17 terms selected from among the first 300 keywords from my corpus (table 2, ordered by keyness):

\begin{tabular}{|l|l|l|l|}
\hline \multicolumn{1}{|c|}{$\begin{array}{c}\text { Property } \\
\text { Claimed }\end{array}$} & \multicolumn{1}{|c|}{$\begin{array}{c}\text { Functional } \\
\text { Devices }\end{array}$} & \multicolumn{1}{|c|}{$\begin{array}{c}\text { Vaguely combined } \\
\text { elements }\end{array}$} & \multicolumn{1}{c|}{ Components } \\
\hline Invention & Engine & Assembly & Portion \\
Embodiment & Vehicle & Mechanism & Member \\
Fluid & Sensor & Unit & Section \\
System & Actuator & Housing & Amount \\
Apparatus & & & \\
\hline
\end{tabular}

Table 2. Selected vague nouns

The words invention and embodiment collocate together in 554 occasions to introduce descriptions of the property being claimed, regardless of the type of invention being described. (See table 3 below) 


\begin{tabular}{|l|r|}
\hline \multirow{4}{*}{ According to +} & an/the alternate + \\
\cline { 2 - 2 } & an/the alternative + \\
\cline { 2 - 2 } & an/the + \\
\cline { 2 - 2 } In accordance with + & another + \\
\hline \multirow{4}{*}{ embodiment of the } \\
present invention
\end{tabular}

Table 3. Typical collocations of embodiment with invention

Table 4 illustrates an alternative to the collocations in Table 3 where the word "embodiment" is dropped (220 occurrences plus 165 occurrences without the adjective "present" in the collocation) and substituted by the word "aspect". The other collocations of "embodiment" tacitly imply the presence of the word combination "the present invention" as (16) shows, so they can be seen as alternative collocations to what tables 3 and 4 exhibit.

\begin{tabular}{|c|c|c|}
\hline According to + & $\mathrm{a} /$ the $[$ ordinal number] + & \multirow{5}{*}{$\begin{array}{l}\text { aspect of the present } \\
\text { invention }\end{array}$} \\
\hline In accordance with + & an alternative $+^{*}$ & \\
\hline \multirow[t]{2}{*}{$\operatorname{In}+$} & an $+*$ & \\
\hline & still/yet another $+*$ & \\
\hline It is $+{ }^{15}$ & a broad + & \\
\hline
\end{tabular}

Table 4. Collocations of aspect with invention

(16) In a preferred embodiment, the brake assembly includes an adjuster mechanism that maintains a predetermined distance between the brake drum and lining assembly. (U.S. Patent 6,169,441)

Both the collocations in tables 3 and 4 respond to the legal requirement of description of the best mode of implementing a specific embodiment (37 Code of Federal Regulations $\$ 1.57 . c .1$ and $\$ 1.71 . b)$. I will only mention here one more collocation for invention that appears at the end of some patent descriptions and whose purpose is to warn that the description covers other potential embodiments of the invention not described in the patent disclosure (Table 5). (17) below is an example of one of these cautionary statements in patents.

\begin{tabular}{|l|l|l|}
\hline This + & \multirow{4}{*}{ invention is not limited +} & by + \\
\cline { 1 - 1 } The present + & in this respect + \\
\cline { 1 - 1 } The + & & thereto. \\
\cline { 3 - 3 } & & to the + [nominal group $]+$ \\
\hline
\end{tabular}

Table 5. Cautionary collocation with invention

(17) Thus, the present invention is not limited by the above description but is defined by the appended claims.(U.S. Patent 7,557,072)

15 "It is" collocates only with those expressions in the central column which are marked with an asterisk. 
Within the part of the patent that identifies the field of the invention we find the combination of the nouns disclosure ${ }^{16}$ and invention with the vague expressions generally and in general.

\begin{tabular}{|l|l|}
\hline The present disclosure relates + & to + \\
\cline { 2 - 2 } The present invention relates + & generally to + \\
This invention is related + & in general to + \\
\hline
\end{tabular}

Table 6.55 main collocations with generally and in general

Most patents are improvements of previous inventions and in these cases, according to 37 Code of Federal Regulations $§ 1.71$ (c):

[...] the description should be confined to the specific improvement and to such parts as necessarily cooperate with it or as may be necessary to a complete understanding or description of it.

Therefore, vagueness inevitably results from the fact that lots of technical details can be assumed to be already known. (18) Illustrates how this vagueness is used to introduce the technical scope and novelty of one invention in the first paragraph of its "Background" section:

(18) An internal combustion engine is a heat engine in which the thermal energy comes from a chemical reaction within the working fluid. (U.S. Patent $6,758,188$ )

The fact that the technical concepts are further specified by creating noun groups reduces only partially the conceptual vagueness as we can see in tables $6,7,8$, and 9 . These tables display the nominal clusters obtained with Antconc using as seeds the nouns in table 2. The absolute frequencies for each of the elements in the corpus appear between parentheses.

\begin{tabular}{|l|l|l|}
\hline \multicolumn{1}{|c|}{ Fluid (5,112) } & \multicolumn{1}{|c|}{ System (7,110) } & \multicolumn{1}{c|}{ Apparatus (2,522) } \\
\hline Fluid pressure (699) & Control system (640) & Control apparatus (208) \\
Brake fluid (675) & Brake system (472) & Lock apparatus (171) \\
Hydraulic fluid (385) & Braking system (262) & Wheel lock apparatus (154) \\
Fluid conduit (201) & Valve system (235) & Image forming apparatus (106) \\
Operating fluid (180) & Storage system (118) & \\
Working fluid (139) & Power system (108) & \\
Fluid passage (123) & Cooling system (104) & \\
Flow of fluid (101) & Drive system (104) & \\
\hline
\end{tabular}

Table 7. Vague nominal groups (I)

\begin{tabular}{|l|l|l|l|}
\hline \multicolumn{1}{|c|}{ Engine (8,519) } & \multicolumn{1}{|c|}{ Vehicle (5,757) } & \multicolumn{1}{c|}{ Sensor (2,045) } & \multicolumn{1}{c|}{ Actuator (1,739) } \\
\hline Combustion engine (896) & Vehicle body (314) & Pressure sensor (166) & Adjustment actuator (118) \\
Internal combustion & Vehicle speed (243) & Speed sensor (148) & Steering actuator (100) \\
engine (715) & Motor vehicle (184) & Temperature sensor (132) & Electric actuator (72) \\
Engine torque (168) & Vehicle brake (139) & Sensor unit (126) & Hydraulic actuator (66) \\
Engine control (168) & Vehicle wheel (117) & Position sensor (97) & \\
Engine rotational speed & Vehicle wheel side (94) & & \\
$(164)$ & & & \\
Engine speed (145) & & & \\
\hline
\end{tabular}

Table 8. Vague nominal groups (II) 


\begin{tabular}{|l|l|l|l|}
\hline \multicolumn{1}{|c|}{ Assembly (4,919) } & \multicolumn{1}{|c|}{ Mechanism (3,538) } & \multicolumn{1}{|c|}{ Unit (4,455) } & \multicolumn{1}{c|}{ Housing (3,096) } \\
\hline Assembly member (1,008) & Drive mechanism (262) & Control unit (595) & Transmission unit (284) \\
Carrier assembly member & Lock mechanism (168) & Electronic unit (236) & Half housing (128) \\
$(777)$ & Transmission mechanism & Mounted unit (213) & Cylinder housing (98) \\
Planet carrier assembly & $(131)$ & Electronic control unit & Valve housing (80) \\
member (652) & Mainspring mechanism & $(159)$ & Upper half housing (74) \\
Gripper assembly (304) & $(107)$ & Unit separators (146) & Pump housing (73) \\
Wheel assembly (124) & Driving mechanism (87) & Sensor unit (126) & \\
& Moving mechanism (86) & Foot-mounted unit (116) & \\
& Supporting mechanism (77) & & \\
& Gear mechanism (74) & & \\
\hline
\end{tabular}

Table 9. Vague nominal groups (III)

\begin{tabular}{|l|l|l|l|}
\hline \multicolumn{1}{|c|}{ Portion (6,355) } & \multicolumn{1}{|c|}{ Member (8,677) } & \multicolumn{1}{c|}{ Section (2,701) } & \multicolumn{1}{c|}{ Amount (2,763) } \\
\hline End portion (277) & Gear member (1,695) & Cross section (231) & Air amount (149) \\
Communication portion & Assembly member (1,008) & Center section (147) & Engine air amount (125) \\
$(160)$ & Sun gear member (876) & Braking section (140) & Amount of fuel (78) \\
Mold portion (136) & Carrier assembly member & Boom section (91) & Injection amount (75) \\
Shaft portion (136) & $(777)$ & Storing section (78) & Deposit amount (69) \\
Upper portion (124) & Ring gear member (716) & Controlling section (70) & Correction amount (64) \\
Holding portion (112) & Planet carrier Assembly & Section view (70) & \\
Rear portion (110) & member (652) & Driving-force storing & \\
Piezoelectric portion (107) & \multicolumn{2}{|c|}{ section (69) } & \\
Head portion (106) & & & \\
Central portion (101) & & & \\
Control portion (99) & \multicolumn{2}{|}{} \\
\hline
\end{tabular}

Table 10. Vague nominal groups (IV)

Those nominal group combinations that may seem more precise, when seen in a broader context have nominal group heads that are vague category identifiers. In examples (19), (20), (21), and (22) the heads portions, circuit, and actuator could have been more specific, but then the scope of the property would be much narrower.
(19) Brake fluid pressure adjusting portions
(20) Brake fluid pressure circuit
(21) Brake fluid pressure control circuit
(22) Brake fluid pressure control actuator

\subsection{Approximators in U.S. Patents}

For Channell (1994: 44), approximators are expressions that designate intervals of numbers, these intervals "increase as a function of the size of the exemplar number", and "the nature of the items being approximated affects the length of interval for which the approximation seems appropriate". 
The World International Property Organization (WIPO) brochure WIPO Guide to Using Patent Information ${ }^{17}$ (page 7) indicates that the claims section of patents contains legal information regarding the scope of the temporary property granted by the authorities. It would not be, therefore, outlandish to find in this section several examples of legal style with its characteristic vagueness. But the information stated in the claims has to be supported by the technical description. For that reason, some expressions in the description section repeat literally the wording found in the claims.

Obviously, due to their frequency ${ }^{18}$ in the corpus, the forms of the indeterminate article $(a, a n)$ play an important role in the vague references of patents. Nevertheless, this form of vagueness is not particular of specialised texts and therefore its study here is not relevant.

Between (7,283 occurrences and ranking $82^{\text {nd }}$ in the keyword list) is used essentially to achieve spatially vague descriptions although it is also used to offer ranges of values that would make the description true. Notice how in (23) the exact position is not determined as a measurement and in (24) there is a range of values that would make the system operational.

(23) A supercharger transmission can be disposed between the ring gear and the transmission or the output shaft downstream of the transmission. (U.S. Patent 5,890,468)

(24) The process as claimed in claim 4, and further comprising dimensioning of the angular geometric coupling of the magnet generator ( $\mathrm{P} 01$ ) with revolutions of the combustion engine such that the or at least one of the alternating voltage half waves (I, II, III) occurs at a rotary angle range between 20 and 5 degrees, preferably 10 to 15 degrees before top dead center (OT). (U.S. Patent 6,761,148)

Least ( $181^{\text {st }}$ keyword and 4,654 occurrences of which 4,232 collocate with at) is used mainly to establish an inclusive interpretation of the metes and bounds ${ }^{19}$ of the property either by indicating that what is being described can be considered one example ("at least one", "at least a/an", or "at least the") or by describing parts or fragments (see the rest of examples in table 11 below).

\begin{tabular}{|l|c|}
\hline At least one & 2,041 \\
\hline At least a/an & 210 \\
\hline At least (a) + [cardinal/ordinal number] & 173 \\
\hline At least a portion of & 96 \\
\hline At least about + [measurement unit or percentage] & 95 \\
\hline At least part of / partially & 91 \\
\hline At least the & 79 \\
\hline At least in part & 75 \\
\hline
\end{tabular}

Table 11. Most frequent collocates of at least

Ranging $\left(1,326\right.$ occurrences and $200^{\text {th }}$ keyword) collocates with the pair "from ... to" in 1,322 occasions. Essentially these collocates present three types of ranges: amounts (25), positions (26), and applications (27). Occasionally, the words about ( 7 occurrences), at least about (3 occurrences), and greater than ( 2 occurrences) appear as reinforcements of the approximative vagueness after the preposition from.

(25) typically ranging from perhaps about $0.2 \mathrm{mph}$ to about $0.3 \mathrm{mph}$ (U.S. Patent $6,763,656)$

(26) via a clearance so as to cover a region ranging from the vicinity of the upper end to the lower end vicinity of the internal door 22. (U.S. Patent $6,764,234$ )

17 Accessible from: http://www.wipo.int/export/sites/www/freepublications/en/patents/434/wipo_pub_1434_03.pdf 18 As this corpus lacks POS tagging, it is not possible to determine without a manual count which of the instances of "a" are indeterminate articles and which are marks of a section or list elements.

19 According to the Manual of Patent Examining Procedure $\$ 2173.05(\mathrm{a})$ at: http://www.uspto.gov/web/offices/pac/mpep/documents/2100_2173_05_a.htm 
(27) The power generator, in turn, can be used to power a number of different devices, ranging from common household appliances (e.g., hair dryer, toaster, etc.), to a heating element associated with a heating device (e.g., hot water heater, furnace, etc.). (U.S. Patent 7,503,418)

Preferably (2,552 occurrences and $71^{\text {st }}$ keyword) and preferred (1,539 occurrences and $188^{\text {th }}$ keyword) behave differently when it comes to presenting approximations. Preferred is used to produce this type of vagueness when it collocates with range ( 23 co-occurrences in five files of the corpus). An example of the co-occurrences of preferred and range can be seen in (28). (29) Is an example of approximation of quantities with preferably.

(28) ...was within a preferred range of $70 \%$ or more in all Examples. (U.S. Patent 7,503,304)

(29) ....and most preferably 85 to 98 weight percent of the solvent... (U.S. Patent 7,557,243)

On the other hand, preferably is frequently found in contexts where vagueness is achieved by approximation of quantities (see table 12 below).

\begin{tabular}{|c|c|c|}
\hline \multirow{8}{*}{ Preferably +} & + about (36) & \multirow{8}{*}{$+[$ measurement $]$} \\
\hline & + at least (49) & \\
\hline & + from $(73)$ & \\
\hline & + between $(28)$ & \\
\hline & + in $[\mathrm{a} /$ the] range $[$ of/from $]$ (37) & \\
\hline & $+[$ comparative $](58)$ & \\
\hline & + within $(16)$ & \\
\hline & $\varnothing(179)$ & \\
\hline
\end{tabular}

Table 12. Occurrences of approximation of quantities with "preferably"

\subsection{Approximating Quantities with Non-numerical Vague Quantities in U.S. Patents}

For establishing this category, Channell (1994: 95) refers to Crystal and Davy. She describes nonnumerical quantifiers as expressions whose truth value can be interpreted within a scale in relation to a context (Channell, 1994: 96-97). These approximators are vague quantifiers because they say nothing absolute about the quantities involved (Channell, 1994: 99). Within this category she identifies the following types: "a + singular quantifier + of + noun", "plural quantifier + of + noun", "vague quantifier + countable noun", and "adverbs of frequency".

Vague quantifiers are not reflected in the list of the first 300 keywords of my corpus. This is something that could be expected because vague quantifiers such as a few, any, certain, every, many, most, other, several, or some are not likely to be used more in my corpus than in the reference corpus. But, the countable nouns appearing among the first 300 keywords collocate frequently with one or more of these vague quantifiers in my corpus.

Table 13 shows the singular quantifiers that appear among the first 300 keywords in my corpus. Example (30) illustrates how "a plurality of + noun" can create a useful vagueness that provides a flexible interpretation of the property defined which benefits the interests of the patent holder.

\begin{tabular}{|l|l|}
\hline A plurality of (1,652) & A member of (286) \\
\hline A ratio of (892) & A section of (216) \\
\hline A set of /subset of (343) & A mixture of (164) \\
\hline \multicolumn{2}{|c|}{ A segment of (52) } \\
\hline
\end{tabular}

Table 13. "a + singular quantifier + of" approximators 
(30) A method as claimed in claim 1 further comprising steps of: equipping a plurality of window shutters over a plurality of operable windows of the building envelope, each window shutter functioning as the one-way venting valve permitting outward air flow only; and opening the windows behind the respective window shutters. (U.S. Patent 6,484,459)

Table 14 displays the second type of non-numerical approximators appearing among the first 300 keywords of the corpus, while (31), (32) and (33) exemplify again how this type of vagueness can lead to an expansive interpretation of where the metes and bounds of the claimed property are.

\begin{tabular}{|ll|l|}
\hline portions of (273) & components of (209) \\
\hline \multicolumn{2}{|c|}{ embodiments of (305) } \\
\hline
\end{tabular}

Table 14. Approximators with plural nouns

(31) The engine 22 includes a lubricating system for providing lubricant to the various portions of the engine. (U.S. Patent 6,763,795)

(32) The foregoing objectives can be accomplished essentially by the addition of a ground heater hose and reel and a large water tank to the components of a pressure washer equipped with a heating system with sufficient capacity for use in a ground heater and preferably a positive displacement pump. (U.S. Patent 6,761,135)

(33) In accordance with different embodiments of the invention, ... (U.S. Patent 6,484,459)

\subsection{Vagueness due to Lack of Interpretation Standard}

Joan Cutting (2007: 224) includes in her category of vague general nouns borderline cases of verbs that are "relatively empty semantically" but "heavily laden pragmatically". Among the first 300 keywords in my corpus we find two of such verbs: can (ranking as $94^{\text {th }}$ in keyness) and may (ranking $105^{\text {th }}$ ). They are vague in the sense that they open the interpretation of the patent disclosure to non-described embodiments.

The verb can is used in 10,371 occasions of which 6,383 are followed by the verb be, or in 247 cases by the combination also be. This verb collocates also in 182 occasions with adverbs such as advantageously, easily, generally, optionally, or readily. Of these collocations with vague adverbs, 65 are in the passive form. Essentially this verb is used to introduce possible modifications and functions of the invention. Table 15 below lists the verbs collocating with this modal verb in my corpus.

\begin{tabular}{|c|c|c|c|}
\hline Accomplished (34) & Controlled (55) & Increased (33) & Produced (36) \\
Achieved (84) & Designed (31) & Made (139) & Provided (92) \\
Added (38) & Determined (35) & Moved (48) & Reduced (78) \\
Adjusted (78) & Done (31) & Obtained (105) & Removed (44) \\
Applied (48) & Employed (42) & Operated (50) & Selected (38) \\
Attached (30) & Engaged (33) & Performed (77) & Shifted (39) \\
Configured (46) & Generated (42) & Placed (31) & Suppressed (38) \\
Connected (76) & Implemented (47) & Prevented (71) & Used (560) \\
& & & Utilized (45) \\
\hline
\end{tabular}

Table 15. Selected verbal collocates of $\boldsymbol{c a n}$

The verb may appears in the corpus on 7,332 occasions, 4,339 of which are followed by the verb $b e$, or in 201 cases by the combination also be. These two collocations are followed mainly by 
nominal groups (237 occurrences, see examples 34,35 , and 36) and the past participles of verbs ${ }^{20}$ (2018 occurrences) in the semantic fields of result, use, position, and means of connection (see examples in table 16 below).

(34) It is contemplated that the transmission 14 may be an electronically controlled automatic transmission, however ... (U.S. Patent 7,556,585)

(35) The supply means may be the hydraulic pump itself, or a charge pump 31. (U.S. Patent $6,745,864$ )

(36) Ball 503 may be a neodymium magnet, as described above, or may be any other permanent magnet, ... (U.S. Patent 7,557,727)

\begin{tabular}{|c|c|c|c|}
\hline Result & Use & Position & Means of connection \\
\hline Accomplished (12) & Actuated (9) & Arranged (25) & Added (38) \\
Achieved (19) & Controlled (28) & Disposed (40) & Attached (40) \\
Applied (46) & Employed (57) & Introduced (10) & Combined (19) \\
Configured (36) & Provided (169) & Located (27) & Connected (51) \\
Formed (89) & Selected (33) & Mounted (37) & Coupled (16) \\
Implemented (31) & Stored (22) & Placed (30) & Engaged (10) \\
Made (135) & Used (414) & Positioned (13) & Mounted (34) \\
Performed (39) & Utilized (36) & Set (21) & Secured (9) \\
\hline
\end{tabular}

Table 16. Selected verbal collocates of may

The list of keywords in my corpus also contains adverbs and adjectives that Mellinkoff (1963: 2022, 301) and Tiersma (1999: 79-82) call words with flexible meaning or weasel words: preferably, preferred, substantially, and selectively. Adams (2004: 85-86), referring to contracts, proposes an unclear classification of these words regarding the point of view used for their interpretation: objective (independently of the interests of the parties involved) or subjective (according to the interests of one of the parties). I assume that these adjectives and adverbs lack an implicit standard to interpret precisely their pragmatic implications.

Preferably (2,552 occurrences) was mentioned in section 6.2 as a quantity approximator. It is also a convenient adverb to describe only the best mode of carrying out the invention, which is a requirement of the USPTO ${ }^{21}$. This adverb co-occurs in 286 occasions with past participles. Table 17 displays this collection of verbs followed by the immediate context options. These verbs can be roughly classified according to the categories shown in table 16 and that the context following these past participles is mainly related to positions and movements.

20 To these you can add 161 more occurrences of the past participles preceded by an adverb.

21 United States Code, Title $35 \S 112$ : "The specification [...] shall set forth the best mode contemplated by the inventor of carrying out his invention.” And also Code of Federal Regulations, Title $37 \S 1.57$ (c)(1). 


\begin{tabular}{|c|c|c|}
\hline is/are preferably + & $\begin{array}{l}\text { accomplished, actuated, adapted, added, } \\
\text { affixed, angled, applied, arranged, assembled, } \\
\text { attached, automated, based, biased, bolted, } \\
\text { brazed, carried, categorised, combined, } \\
\text { composed, comprised, conducted, configured, } \\
\text { connected, constituted, constructed, controlled, } \\
\text { cooled, coupled, decelerated, designed, } \\
\text { detached, determined, disposed, dissolved, } \\
\text { distributed, divided, edged, embodied, } \\
\text { employed, equalized, equipped, excavated, } \\
\text { exhausted expelled, fabricated, fed, filled, } \\
\text { fixed, formed, generated, heated, implemented, } \\
\text { improved, incorporated, injected, inserted, } \\
\text { integrated, interposed, joined, limited, } \\
\text { located, machined, maintained, manufactured, } \\
\text { measured, modified, monitored, mounted, } \\
\text { normalized, obtained, operated, oriented, } \\
\text { performed, placed, positioned, pressed, } \\
\text { produced, provided, reduced, removed, } \\
\text { restricted, returned, rounded, routed, sealed, } \\
\text { secured, selected, separated, sized, spaced, } \\
\text { spliced, started, stored, subjected, substituted, } \\
\text { supported, tapered, tilted, uncoupled, used, } \\
\text { welded + }\end{array}$ & $\begin{array}{l}\text { about, according to, adjacent, after, } \\
\text { along, among, and joined by, and in } \\
\text { abutment with, as, at, based upon, } \\
\text { basically to, below, between, by, } \\
\text { close to, directly in, during, even } \\
\text { in, for, from, generally, gradually, } \\
\text { greater, in, inside, integrally, into, } \\
\text { near, of, on, out, particularly, } \\
\text { posteriorily, primarily, rotationally, } \\
\text { separately, similarly, slightly, } \\
\text { so that, substantially, such that, } \\
\text { through, to + infinitive, to, together, } \\
\text { toward, underneath, up, using, } \\
\text { when, while, with, within, without }\end{array}$ \\
\hline
\end{tabular}

Table 17. Past participles modified by preferably

Preferred (1,561 occurrences) is also instrumental in writing descriptions that present the best mode requirement already mentioned. Its most frequent collocation with a noun is with embodiment and embodiments ( 880 occurrences, $56 \%$ of the total). This high frequency is expected as embodiment is used to refer to any patented invention and many patents describe several best modes for carrying out the invention. (See table 3 for the most frequent preceding context of preferred when it collocates with embodiment).

Substantially (1,171 occurrences and $233^{\text {rd }}$ keyword) modifies mainly adjectives that form part of nominal groups in this corpus. The adjectives modified by this adverb correspond to more than $40 \%$ of its collocations. The 3 main semantic fields covered by these modified adjectives are shape (37), position (38), and mode of performance (39).

(37) ... a key lock assembly that includes a substantially cylindrical canister. (U.S. Patent 6,634,195)

(38) ... such that the leading segment 250 is substantially contiguous with a corresponding surface of the roadway. (U.S. Patent 7,503,418)

(39) ... a retracted position in which said first gripper assembly permits substantially free relative movement between said first gripper assembly and said inner surface. (U.S. Patent 6,679,341)

The adverb substantially is preceded by 70 expressions that are related to the semantic fields of movement (40), position (41), and means of connection (42).

(40) ... it is also possible to cause the front end 29 to pivot in a substantially horizontal plane relative to the rear end 31. (U.S. Patent 7,481,604)

(41) ... such that the transducer 36 is positioned substantially near a desired final position.. (U.S. Patent $6,295,857)$ 
(42) Bladder assembly 404 comprises generally rigid tube portions 416 and 417 attached to each end of a substantially tubular inflatable engagement bladder 406. (U.S. Patent 6,745,854)

Selectively $\left(1,066\right.$ occurrences and $190^{\text {th }}$ keyword) is used frequently to avoid being specific about the method used for carrying out some function of the invention. The typical contexts in which this adverb is used seem to be the following:

(a) [part or parts of the invention] $+[$ is/are $]+$ selectively + [past participle /adjective] (typical of the description sections) (374 occurrences)

(b) [part or list of parts of the invention] + for + selectively + ["-ing" verb form] (typical of the claims section) (109 occurrences)

(c) [part or list of parts of the invention] + to + selectively + [infinitive] (typical of the claims section) (88 occurrences)

It is also worth mentioning that this adverb tends to prefer the modification of verbs and deverbal adjectives within the semantic field of means of connection. Table 18 below shows the most frequent verbal and derivate adjective co-occurrences. Vaguely describing the way that elements are connected together reduces the possibilities of introducing non-obvious improvements to an invention. Therefore, the patentees increase the scope of the property covered by their patent.

\begin{tabular}{|l|l|}
\hline \multirow{5}{*}{ Selectively +} & Connect (13) \\
\cline { 2 - 2 } & Connectable (419) \\
\cline { 2 - 2 } & Connected (2) \\
\cline { 2 - 2 } & Connectible (2) \\
\cline { 2 - 2 } & Connecting (10) \\
\cline { 2 - 2 } & Connects (11) \\
\hline & Engagable (2) \\
\cline { 2 - 2 } & Engage (7) \\
\cline { 2 - 2 } & Engageable (9) \\
\cline { 2 - 2 } & Engaged (42) \\
\cline { 2 - 2 } & Engages (3) \\
\hline & Engaging (7) \\
\hline & Interconnecting (60) \\
\cline { 2 - 2 } & Interconnects (10) \\
\hline
\end{tabular}

Table 18. Selectively and "means of connection" verbs and deverbal adjectives

Engberg \& Heller (2008: 155-162), following Bhatia (1993: 113-118) mention the vagueness that can be achieved in regulations by the use of conditional sentences. In patents, like in regulations, conditional subordinate sentences are used to achieve all-inclusiveness while remaining precise and clear enough for the required communicative purposes (Bhatia, 1993: 117). The conjunction if introducing conditional subordinate sentences appears in 4,684 occasions in my corpus. This conjunction is used to modify the scope of the effects and functions of the inventions described, which according to Pinkal's approach to vague language has the effect of creating a lack of true value. In other words, vagueness introduces a degree of flexibility that makes room for several possible interpretations of the invention being described.

(43) The dilution factor of 1000 may be varied if desired to produce a preferred concentration of catalyst in the final product. If water is used in Step 4, it is preferred to add 1 part of the substance produced to 20 parts of isopropyl alcohol and/or MTBE, which may then be added to fuel in Step 5. If water is used in Step 4 as the mixing liquid or solvent and the fuel is diesel, the product of Step 4 may be added directly to diesel fuel at a rate of $50 \mathrm{ppm}$ or less. (U.S. Patent 7,503,944) 
(44) In one embodiment, the threshold value chosen represents the point when the user's foot is in the air and is on the ground for equal time periods during a complete footstep (i.e., when $\mathrm{Tc}=\mathrm{Ta}$ ). These threshold values may be readily calculated given that, for each complete footstep, $\mathrm{Ts}=\mathrm{Tc}+\mathrm{Ta}$. If the user's foot is on the ground longer than it is in the air during a complete footstep, it may be determined that the user is walking. Conversely, if it is determined that the user's foot is in the air longer than it is on the ground, it may be determined that the user is running. (U.S. Patent 7,617,071)

In (43) the combination of conditional sentences with the modal may and the adjectives preferred and desired allow for adding details and optional variations to the best mode of the invention. Nevertheless, these additions are vague enough to cover more than one possible interpretation.

In (44) we have to consider that the inventors are not required to present a working model of the invention. Their description of the invention has to be persuasive in terms of the feasibility of the invention. Therefore, the combination of the verb may with the conditional sentences provides a description which is at the same time precise enough to show the invention is feasible and general enough to cover several circumstances that would make the invention feasible.

\section{Conclusions}

A short answer to the question of "how vague can your patent be?" would be 'quite'. Unfortunately, this answer is rather vague itself. This paper has not provided a precise answer in terms of up to how much vagueness is accepted by U.S. institutions and law, but it has reviewed a range of strategies used in U.S. patent claims to deliberately achieve vagueness.

Those who have studied vagueness before from the point of view of linguistics and legal drafting, despite the different taxonomies that they use, seem to coincide in that vagueness is achieved by lack of precision. This imprecision derives mainly from using category nouns, imprecise quantification, and expressions whose interpretation cannot be based on a clearly established standard.

Channell's explanation for using vagueness is perfectly compatible in the case of the U.S. Patents with the USPTO requirements and the commercial interests of the patent applicants. Therefore a more complete answer to the initial question would be that you can be vague enough to protect your financial interests, but precise enough to meet the disclosure requirements of the patent office. In other words, vagueness can be adapted to the type of invention being patented. Of course, vagueness allows for interpretation so there might be more or less aggressive approaches to its use. There is always the risk that a patent acceptable for the USPTO is invalidated by a court on the grounds of insufficient description of the novelty, non-obviousness, or differences from other existing technology.

The approach followed centred on the use of linguistic vagueness on the 300 words with the highest keyness factor according to the Log-likelyhood test. This approach detects the types of vagueness which are more frequent in patents when compared to the BNC. Nevertheless, it has the disadvantage that some frequent words used to achieve vagueness do not appear in this list as they are very common in any kind of text. An alternative approach that can solve this problem would be combining a frequency list with the keyword list.

\section{References}

Adams, Kenneth A. 2005: A Manual of Style for Contract Drafting. Chicago: American Bar Association.

Anesa, Patrizia 2007: Vagueness and Precision in Contracts: a Close Relationship. In Linguistica e Filologia 24, 7-38.

Arntz, Reiner/Sandrini, Peter 2007: Präzision versus Vagheit: Das Dilemma der Rechtsprache im Licht von Rechtsvergleich und Sprachvergleich. In Antia, Bassey Edem (Editor) Indeterminacy in Terminology and LSP : Studies in Honour of Heribert Picht. Amsterdam: John Benjamins Publishing Company, 135-155.

Bazerman, Charles 1999: The Languages of Edison's Light. Cambridge, Massachusetts:The MIT Press.

Bazerman, Charles 1998: Emerging perspectives on the many dimensions of scientific discourse. In Martin, J.R./Veel, Robert (eds), Reading Science: Critical and Functional Perspectives of Discourses of Science, 15-30. London: Routledge. 
Bazerman, Charles 1997: Performatives constituting value: the case of patents. In Gunnarson, B.L./Linell, P./Nordberg, B. (eds), The Construction of Professional Discourse. London: Longman, 42-53.

Bazerman, Charles 1993: Patent Realities: Legally Stabilized Texts and Market Indeterminacies. In Hultberg, John (ed.), The Narrative Construction of the Anxious Object: Papers from the 4S/EASST Conference. Göteborg 12-15 August 1992, 5-12.

Bhatia, Vijai K. 2005: Specificity and Generality in Legislative Expression: Two Sides of the Coin. In Bhatia, V.K./ Engberg, J./Gotti, M./Heller, D. (eds.), Vagueness in Normative Texts. Bern: Peter Lang AG, 337-356.

Bhatia, Vijai K. 1993: Analysing Genre: Language Use in Professional Settings. London: Longman.

Brugnoli, Patrizia 2007: Il Testo Giuridico, Apolide in una Tipologia dei Testi? Alcune Riflessioni. In Revista de Llengua i Dret, núm. 47, 43-59 [online]. http://www10.gencat.net/eapc rld/revistes/copy4 of Revista_prova 2/article.2008-09-22.9479688951/ca/at download/adjuntdefecte (14.01.2011)

Burge, David A. 1999: Patent and Trademark: Tactics and Practice. New York: John Wiley \& Sons Inc.

Butt, Peter/Castle, Richard 2006: Modern Legal Drafting: A Guide to Using Clearer Language. Cambridge: Cambridge University Press.

Channell, Joanna 1994: Vague Language. Oxford: Oxford University Press.

Cutting, Joan (ed.) 2007: Vague Language Explored. New York: Palgrave MacMillan.

Dascal, Marcelo/Wróblewski, Jerzy 1988: Transparency and Doubt: Understanding and Interpretation in Pragmatics and in Law. In Law and Philosophy 7. Dordrecht: Kluwer Academic Publishers, 203-224.

DeMatteis, Bob/Gibbs, Andy/Neustel, Michael 2006: The Patent Writer: How to Write Successful Patent Applications. New York: SquareOne Publishers.

Endicott, Timothy 2005: The Value of Vagueness. In Bhatia, V.K./Engberg, J/Gotti, M./Heller, D. (editors) Vagueness in Normative Texts. Bern: Peter Lang AG, 27-48.

Endicott, Timothy 2001: Law is Necessarily Vague. In Legal Theory, 7. Cambridge University Press, 379-385.

Endicott, Timothy/Spence, Michael 2005: Vagueness in the Scope of Copyright. In 121 Law Quarterly Review, 657680.

Engberg, Jan/Heller, Dorothee 2008: Vagueness and Indeterminacy in Law. In Bhatia, V.K./Candlin, C.N./Engberg, J. (eds.), Legal Discourse across Cultures and Systems, 145-168. Hong Kong: Hong Kong University Press.

Frade, Celina 2002: Mitigating Conflict in Arbitration Clauses through Language. In LSP \& Professional Communication, Volume 2, Number 1, 8-26. [online]. http://cjas.dk/index.php/LSP/article/viewFile/1941/1944 (2.12.2010)

Frobert-Adamo, Monique 2000: Influence of Linguistic Patterns on the Transfer of Strategic Information: A Diachronic Study of the Rhetoric of Patent Applications in the United States. In Hager, Peter J./Schreiber, Howard Jeffrey (eds.), Managing Global Communication in Science and Technology. New York: John Wiley \& Sons, Inc, 153-178.

Gordon, Thomas T./Cookfair, Arthur S. 2000: Patent Fundamentals for Scientists and Engineers. Boca Raton, Florida: Lewis Publishers - CRC Press LLC.

Howells, John/Sholderer, Joachim 2008: How do Firms Use the Information in Patent Disclosures? An Empirical Research Proposal. In CORE - Centre for Organizational Renewal and Evolution, 2008. 9 s. (Working paper CORE; 2008-04). Aarhus: Aarhus School of Business [online]. http://research.asb.dk/research/how do firms use the information_in_patent_disclosures(207059)/ (10.10.2010)

Ivanič, Roz 1991: Nouns in Search of a Context: A Study of Nouns with Both Open - and Closed - System Characteristics. In IRAL: International Review of Applied Linguistics in Language Teaching, 29, 93-114.

Kennedy, Christopher 2002: The Landscape of Vagueness. Ms., Northwestern University. Seen 17/11/2009 [online]. http://ocw.mit.edu/courses/linguistics-and-philosophy/24-979-topics-in-semantics-fall-2002/lecture-notes/vagueness.pdf $(9.09 .2010)$

Keefe, Rosanna 2000: Theories of Vagueness. Cambridge: Cambridge University Press.

Mellinkoff, David 1963: The Language of the Law. Eugene: Resource Publications.

Myers, Greg 1996: Strategic Vagueness in Academic Writing. In Ventola, Eija/Maurannen, Anna (eds), Academic Writing: Intercultural and Textual Issues. Amsterdam: John Benjamins Publishing Company, 3-18.

Myers, Greg 1995: From Discovery to Invention: The Writing and Rewriting of Two Patents. In Social Studies of Science 25/1, 57-105.

Nussbaumer, Markus 2005: Zwischen Rechtsgrundsätzen und Formalarsammlung: Gesetze brauchen (gute) Vagheit zum Atmen. In Bhatia, V.K./Engberg, J./Gotti, M./Heller, D. (eds), Vagueness in Normative Texts. Bern: Peter Lang AG, 49-72.

Pinkal, Manfred 1995: Logic and Lexicon. Dordrecht: Kluwer. 
Prampolini, Massimo 1998: Il concetto di vaghezza. In Albano Leoni, F./Gambarara, D./Gensini, S./Lo Piparo, F./Simone, R. (eds), Ai limiti del linguaggio. Vaghezza, significato e storia, volume in onore di T. De Mauro. Roma-Bari: Laterza, 107-122.

Quine, Willard van Orman 1960: Word and Object. Cambridge, MA. :The MIT Press.

Rayson, Paul/Berridge, Damon/Francis, Brian 2004: Extending the Cochran rule for the comparison of word frequencies. In JADT 2004: 7es Journées Internationales d'Analyse statistique des Données Textuelles [online]. http:// eprints.lancs.ac.uk/12424/1/rbf04 jadt.pdf (13.12.2010)

Rayson, Paul/Garside, Roger 2000: Comparing Corpora using Frequency Profiling. In WCC '00 Proceedings of the workshop on Comparing Corpora - Volume 9 [online]. http://www.comp.lancs.ac.uk/ paul/publications/rg acl2000.pdf (13.12.2010)

Roberts, Gwilym 2007: A Practical Guide to Drafting Patents. London: Sweet \& Maxwell Limited.

Russell, Bertrand 1923: Vagueness. In Australasian Journal of Philosophy and Psychology, 1 (June 1923), 84-92.

Solan, Lawrence M. 2005: Vagueness and Ambiguity in Legal Interpretation. In Bhatia, V.K./Engberg, J./Gotti, M./ Heller, D. (eds), Vagueness in Normative Texts. Bern: Peter Lang AG, 73-96.

Stim, Richard 2006: Patent, Copyright \& Trademark: An Intellectual Property Desk Reference. Berkeley, California: Nolo.

Tiersma, Peter M. 1999: Legal Language. Chicago: The University of Chicago Press.

Van Deemter, Kees 2010: Not Exactly: in Praise of Vagueness. Oxford: Oxford University Press.

Williamson, Timothy 1996: Vagueness. Florence, KY, USA: Routledge. 